\title{
MULTI BODY VIBRATION ANALYSIS OF A THREE-AXIS SLIDE FOR MASS DAMPER DESIGN
}

\author{
P. Hadraba ${ }^{*}$ Z. Hadaš ${ }^{\star *}$
}

\begin{abstract}
Vibration analysis has a key role in machine design. However, the modal analysis based on FEM (finite element method) could be too slow for the machine with changeable topology. This work presents rigid body based model in MSC ADAMS for a low-frequency vibration analysis of a multi-spindle lathe slide. This example represents a three-axis motion system with dominant contact stiffness in linear guideways. The model was used for cutting stability estimation and for dynamic damper development. The validation of this model was done by experimental measurement and by FEM model calculation. In the future, due to its computational efficiency, the model could be used for artificial topological optimization of this machine.
\end{abstract}

Keywords: dynamic analysis, linear guideways, mass damper, vibration, chatter, slide dynamic modelling

\section{Introduction}

Design of modernproduction machines focuses on machine speed as well as on precision, but the growth of speed causes new obstacles. This paper describes a problem analysis of a new prototype of a multi-spindle automatic lathe, where the traditional dovetail slides, used in classical concept, were replaced by a ball bearing slides. The speed of slide movement increased in all direction and frictional losses were reduced. However, a new problem arose in the dramatical decrease of whole system damping. Due to this fact, the amplitudes of vibration increased and the slide was not suitable for machining.

In the measurement was observed that the low stability in machining process is caused by chatter. The dominant mode has a low-frequency pitch of the whole system. MSC Adams with Matlab Simulink were chosen to analyze this issue more deeply. MSC Adams was used to design 3D parametrized model and to export it into the state space matrix for the following Matlab processing. A similar analysis was described by Štetina and B řezina (2014).

The phenomenon of vibration in a linear ball guideway was described in several articles. Jeong and Kang (2014) defined equivalent stiffness of linear guideway for stage systems. Yi and Kim (2008) described the linear motion guideway dynamic properties by combining experimental data and FEM modal analysis. Hung and Lin (2016) described the problem of modeling milling machine with a hybrid guideway system. Hung (2009) focused on the lode effect on vibration frequency and amplitude. Pisarski and Bajer (2011) described semi-active control of a damping in linear guideways, however, this method is too expensive for our problem. The most effective and least costly way to suppress high amplitude and low cutting stability, is to change system mode by a mass damper. The use of the mass damper was described by Said and Vasant (2017). Chang (1999) dealt with the mass damper parameter optimization, mostly with the mass and damping parameters.

This paper firstly presents a parametric rigid-body model with flexible a contact model of a linear ball guideway for vibration analysis of the multi-spindle lathe slide, secondly describes the use of this model for mass damper parameter calculation by minimizing maximal vibration amplitude of system.

\footnotetext{
Ing. Petr Hadraba: Institute of Production Machines,Systems and Robotics, Brno University of Technology; Technická 2896/2; 616 69, Brno; CZ, Petr.Hadraba@vutbr.cz

** doc. Ing. Zdeněk Hadaš Ph.D.: Institute of Solid Mechanics, Mechatronics and Biomechanics, Brno University of Technology; Technická 2896/2; 616 69, Brno; CZ, hadas@fme.vutbr.cz
} 


\section{Model}

There were two possible methods for the slide modelling. The first option was a directly convert CAD model into MSC Adams. The other variant was to use only data from the CAD model to define each part by its mass, center of mass, and moments of inertia. The disadvantage of the second variant is that the whole model geometry must be defined again. On the other hand, the whole system could be defined by fewer points, so it is easier to parameterize. The second variant was chosen for the three-axis slide model. The slide was represented as a three-independentrigid body model defined by mass and its moments of inertia about the center of mass. The center of mass, as well as position of the guideway contact, were defined by markers and parameterized by a slide position range.

Contacts in the liner ball guideways were substituted by a two-axis spring and damper in the center of each guideway. The stiffness coefficients were estimated from the static stiffness coefficient (defined by the guideway producer) and from experimental measurement. Ball screw linear actuators were modeled as springs. These springs represented rod uniaxial normal stiffness parameterized by the rod length.

a)

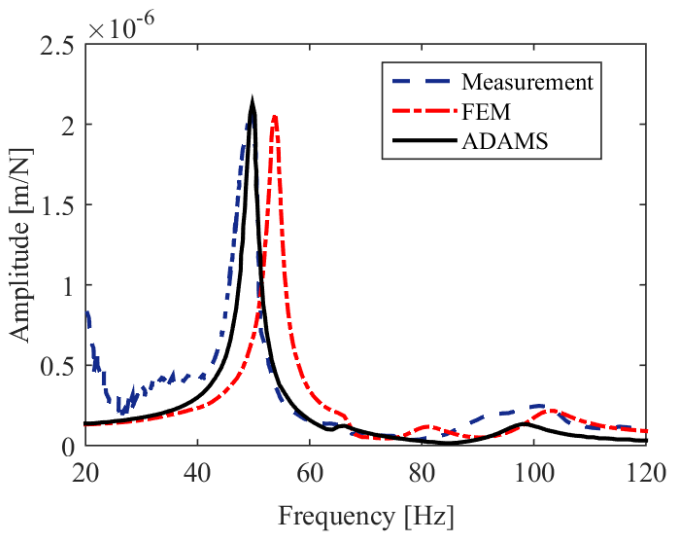

b)

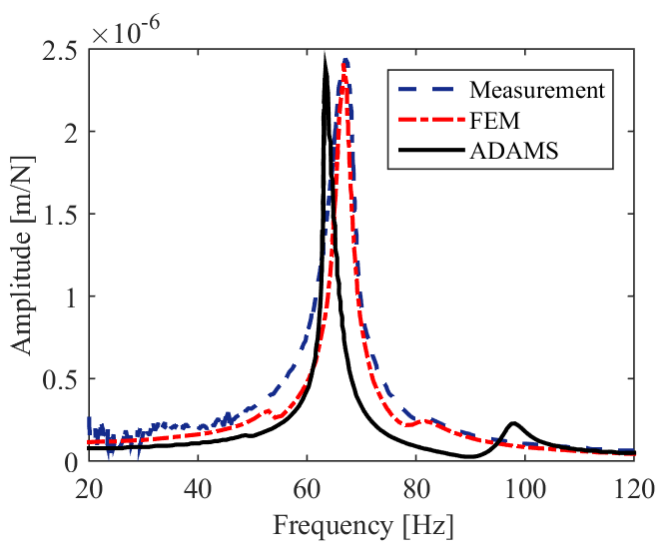

Fig. 1: The amplitude-frequency characteristics in $Y(a)$ and $X(b)$ direction. Comparison of measured data, Creo Simulate FEM model and Adams rigid model.

The comparison between FEM, Adams rigid body based model and experimental measurement could be seen in Fig.1. It shows good model behaviour in the Y-axis as well as in the X-axis. The hypothesis that the contact in the linear ball guideway has a key role for this system was proved. For that reason, the Adams rigid body model could be used for the cutting stability estimation.

Fig. 1 also shows a low damping coefficient in the contact between axis, it is approximately $2 \%$ of the critical damping in both main axis. The low damping coefficient is related to low chatter stability. Tlusty (2000) describes the relation between chatter and negative real part of system transfer function.

Regarding the mass damper design, this model could be expanded with the input and output channel to allow cyclic simulation with variable inputs. In general, it could be modified with any kind of function in Matlab or Simulink for various problem-solving. This method allows calculation of a large amount of data in a relatively short computational time.

\section{Results and discussion}

Fig. 2 shows first and second vibration mode; the undeformed system is in red. These modes are same for all positions in the slide.The frequency and amplitude are different. The triangular red shape in the picture is the knife position. This point is rigidly connected with the Z-axis slide (green). The vibration mode shapes calculated in MSC Adams are same as in the FEM. This fact shows the dominance of linear ball guideway in vibration as well as its influence on the chatter stability in the machining process. After more than 6,500 simulations with variable parameters, the maximal amplitude map of the whole system was made. Each axis of the system depended on mass damper parameter. Combinations of mass and damping were simulated to design mass damper. These combinations were simulated for five undamped $(f=\sqrt{ } \underline{k} / m)$ frequencies of mass damper near the natural frequency of slide. 


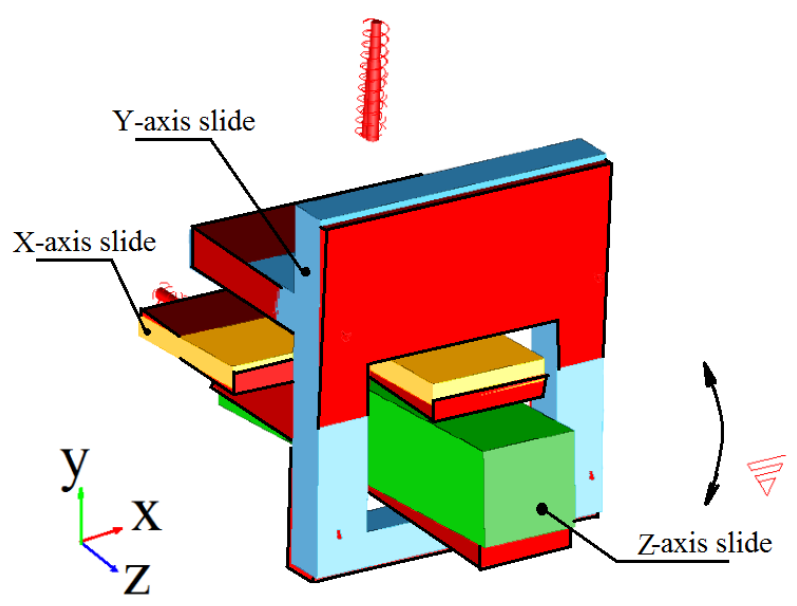

(a)

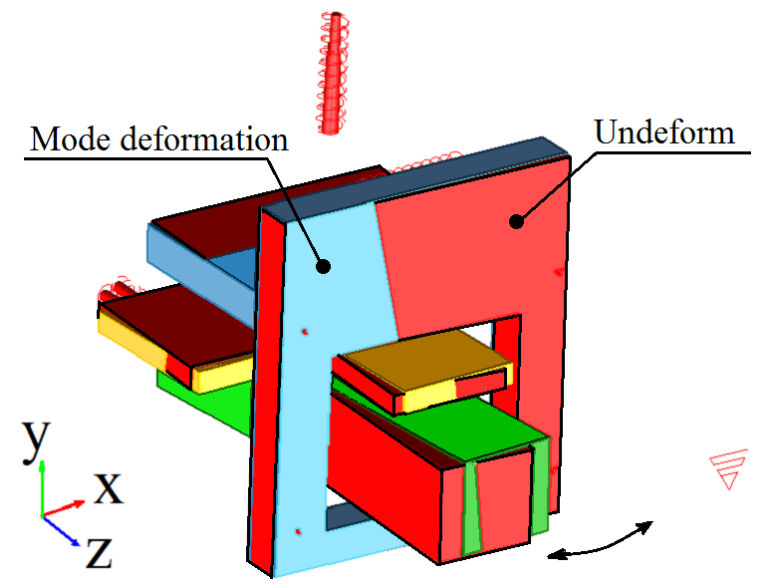

(b)

Fig. 2: First vibration mode pitch $52 \mathrm{~Hz}$ (a) and second vibration mode yaw $66 \mathrm{~Hz}$ (b)

These simulations were done in each position of the slide and were summarized according to a cost function.

$$
C_{m \xi}=\sum_{x} \sum_{y} \sum_{z} \max (a(x, y, z)) \cdot p(x, y, z)
$$

This cost function $C$ represents evaluate the probability $p$ of parting off operation in this position and maximal amplitude $a$ in this position. The Fig. 3 shows the results of these simulations for Y direction. In this figure, it could be seen that for mass damper tuned into original frequencies, there is low parameter dependency. However, lower maximal amplitude could be reached by tuning into lower frequency (42$48 \mathrm{~Hz}$ ) and with higher mass and damping in a 20-35\% range of critical damping. For the slide productivity and its good response, any additional mass is inconvenient. Therefore, the compromise between those factors should be found.
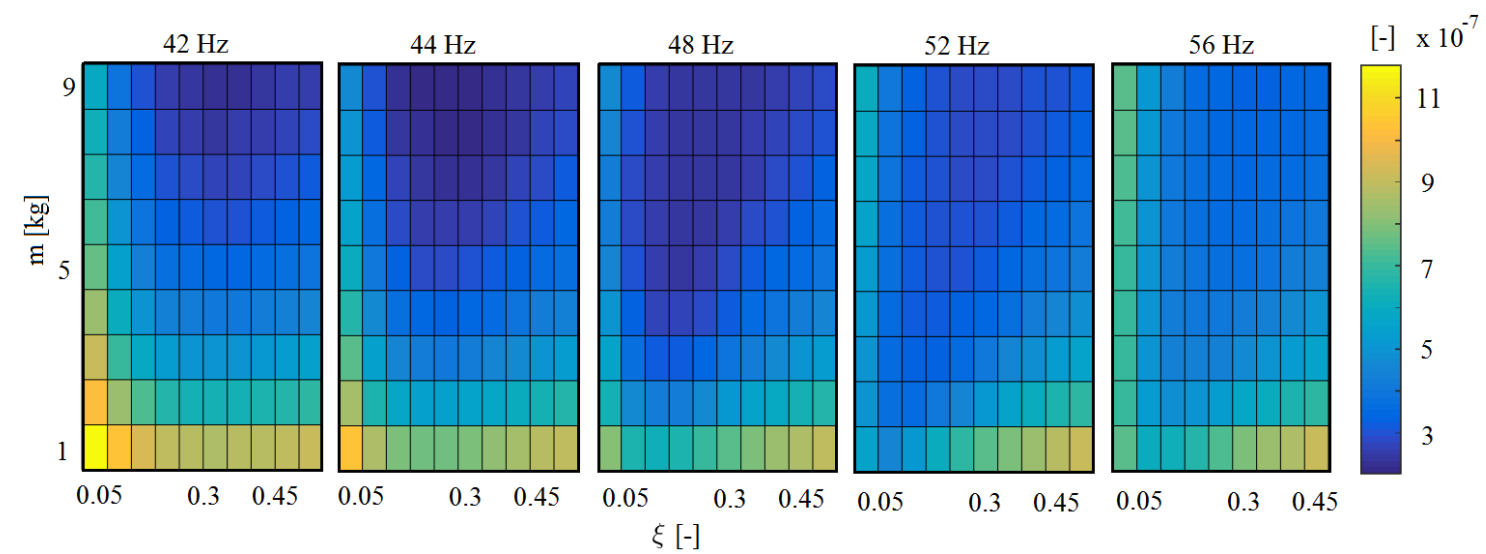

Fig. 3: Cost function of whole system depending on mass damper parameter.

The $\mathrm{Y}$-axis dependence of the amplitude and natural frequency position according to slide $\mathrm{Z}$-axis position is showed in Fig. 4, the mass damper reduces maximal amplitude on one-third of the original system amplitude. These parameters of mass damper oriented on the slide position where parting off operations are situated.

\section{Conclusion}

This paper has described the model of the system with variable topology with dominant contact stiffness. In the low-frequency spectrum, the rigid base body model with stiff contact could be alternative to time 


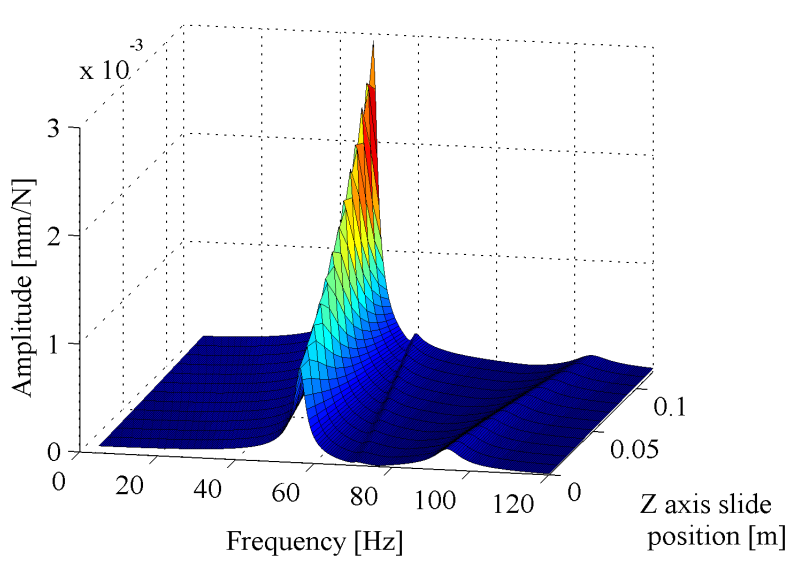

(a)

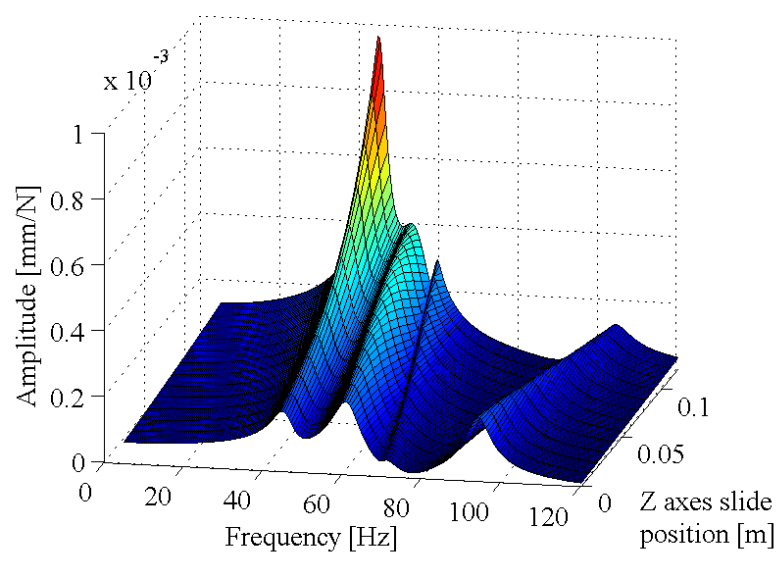

(b)

Fig. 4: $Y$ axis amplitude frequency diagrams with dependence of the $Z$ axes slide position, (a) original system (b) system with $3 \mathrm{~kg}$ mass damper.

demanding finite element method. This model was used for the mass damper design, which modifies dynamic behavior of the whole system and increases cutting stability. The future work with this model will focus on a more complex type of mass damper, mostly on nonlinear types. Presented slide model could be expanded by a spindle model presented by Hadraba and Hadaš (2018). This spindle-slide connection allows description of the whole machining process and relation between these machine parts with the regulation impact. The experimental damper designed according to this paper is being manufactured. The results of this damper and experimental optimization will be presented in the next article.

\section{Acknowledgments}

This work is an output of BUT research project Reg. No. FSI-S-17-4477 — Zvyšování technické vyspělosti výrobních strojů a zařízení

\section{References}

Chang, C. C. (1999), Mass dampers and their optimal designs for building vibration control. Engineering Structures, Vol 21, No.5, pp 454 - 463.

Hadraba, P. and Hadaš, Z. (2018), Dynamic Analysis of Multispindle Lathe. Advances in Intelligent Systems and Computing, Vol 644, No.1, pp 321-329.

Hung, J., Lin, W., Chen, Y. J. and Luo, T. L. (2016), Investigation of the machining stability of a milling machine with hybrid guideway systems. Applied Sciences (Switzerland), Vol 6, No.3.

Hung, J. P. (2009) Load effect on the vibration characteristics of a stage with rolling guides. Journal of Mechanical Science and Technology, Vol 23, No.1, pp 89-99.

Jeong, J. and Kang, E. and Jeong, J. (2014) Equivalent stiffness modeling of linear motion guideways for stage systems. International Journal of Precision Engineering and Manufacturing, Vol 15, No.9, pp 1987-1993.

Pisarski, D. and Bajer, C. I. (2011) Smart suspension system for linear guideways. Journal of Intelligent and Robotic Systems: Theory and Applications, Vol 62, No.3-4, pp 451-466.

Said, E. and Vasant, M. (2017) Research developments in vibration control of structures using passive tuned mass dampers. Annual Reviews in Control, Vol 44, pp 129 - 156.

Tlusty, G. (2000) Manufacturing processes and equipment. NJ: Prentice-Hall, Upper Saddle River.

Yi, Y. -. and Kim,Y. Y. and Choi,J. S. and Yoo,J. and Lee,D. J. and Lee,S. W. and Lee,S. J. (2008) Dynamic analysis of a linear motion guide having rolling elements for precision positioning devices. Journal of Mechanical Science and Technology, Vol 22, No.1, pp 50-60.

Štětina, J., Březina, T., Vetiška, J. and Hadaš, Z. (2014), Multibody model of Heavy Machine Tool. In: Proceedings of the 16th International Conference on Mechatronics, Mechatronika 2014, pp 266-270. 